\title{
A Study of Autonomic Manifestations of Diabetes Mellitus in a Rural Medical College
}

\author{
Abhirami $K^{1}$, Shashidhar $\mathbf{G}^{2}$, Kavitha $\mathrm{R}^{3}$ \\ ${ }^{1}$ Junior Resident, Department of General Medicine, ${ }^{2}$ Professor, Department of General medicine, MVJ Medical College \& \\ Research Hospital, Hoskote, ${ }^{3}$ Junior Resident, Department of General medicine, MVJ Medical College \& Research Hospital, \\ Hoskote, Karnataka, India
}

Corresponding author: Dr Shashidhar G, Department of General Medicine, MVJ Medical college \& Research Hospital, Hoskote, Karnataka, India

DOI: http://dx.doi.org/10.21276/ijcmsr.2020.5.2.27

How to cite this article: Abhirami K, Shashidhar G, Kavitha R. A study of autonomic manifestations of diabetes mellitus in a rural medical college. International Journal of Contemporary Medicine Surgery and Radiology. 2020;5(2):B109-B112.

\section{A B S T R A C T}

Introduction: Diabetes Mellitus is a major health problem worldwide. Autonomic neuropathy is a disabling complication of Diabetes Mellitus. This study aims to detect cases of autonomic neuropathy and its significant correlation with Diabetes in a rural medical college.

Material and methods: The study was carried out on 50 patients with diabetes mellitus, in the Department of Medicine, at MVJ Medical college and research Hospital, Hoskote over the period of 18 months (from June 2017 to November 2018).

Results: Average age group of patients was 45-60 years. Impotence was the commonest symptom(35\%) followed by postural giddiness (32\%). Nearly $64 \%$ of cases had positive Autonomic scores. $77 \%$ of cases with polyneuropathy had positive autonomic scores. Among the cases the mean $\mathrm{HbA1C}$ was $8.24 \pm 2.59 \%$ in those with positive Autonomic scores. $46 \%$ cases had Prolonged Corrected QT-interval. Among them the corrected QT-interval was 6.46 \pm 0.79 seconds. There is a significant decrease in number of tests being positive among those who take both insulin and Oral Hypoglycemics, as against those who take either one.

Conclusions: There is an increased incidence of autonomic neuropathy among Diabetics. Proper treatment regimens and stricter lifestyle modifications help in controlling the glycemic status, which reduce the incidence of Autonomic dysfunction.

Keywords: Autonomic neuropathy, Glycosylated Haemoglobin, Corrected QT-interval, Impotence, Polyneuropathy

\section{INTRODUCTION}

Autonomic neuropathy is an important complication of diabetes resulting in increased morbidity and mortality. Autonomic dysfunction is common although symptomatic autonomic neuropathy is rare. Thus diabetic autonomic neuropathy can take two forms: subclinical neuropathy, which is diagnosed by the presence of abnormal autonomic function tests, and symptomatic or clinical neuropathy, which presents with the classic signs and symptoms. Autonomic neuropathy can involve many systems, including cardiovascular, gastrointestinal, genitourinary, and respiratory systems.Cardiovascular autonomic neuropathy represents the most serious complication. Although symptomatic autonomic neuropathy is rare, many patients with abnormal autonomic tests do not respond appropriately to cardiovascular stresses because of impaired autonomic reflexes and this leads to an approximately five-fold risk of mortality. ${ }^{1-4}$ Current research aimed to study the presenting manifestations of autonomic dysfunction in diabetes mellitus and to observe the pattern of prevelance of autonomic dysfunction.

\section{MATERIAL AND METHODS}

A prospective study was done on 50 patients diagnosed with diabetes, admitted in department of medicine at MVJ Medical college \& research hoapital over a period of 18 months (June 2017 to November 2018).

Inclusion Criteria: The study included subjects, diagnosed with diabetes based on Criteria for diagnosis of Diabetes ${ }^{5,6,7}$, irrespective of age, sex, duration and type of diabetes.

\section{Criteria for diagnosis of Diabetes}

A fasting (of more than 8 hours) blood glucose levels of 126 $\mathrm{mg} / \mathrm{dl}$ or more (OR)

Two-hour Post-prandial blood glucose levels of $200 \mathrm{mg} / \mathrm{dl}$ or more (OR)

Symptoms of Diabetes with Random BloodGlucose concentration of $200 \mathrm{mg} / \mathrm{dl}$ or more (OR)

$\mathrm{A} 1 \mathrm{C}>/=6.5 \%$; tested in a lab that is NGSP certified and standardized to DCCT assay.

\section{Exclusion Criteria}

1. Patients with severe anemia, congestive cardiac failure, renal failure, obstructive lung disease, liver diseases and 
cardiac arrhythmias.

2. Patients with exposure to Alcohol, lead, Neurotoxic drugs, anti-hypertensives and drugs affecting the autonomic function

3. Patients with central or peripheral neuropathies due to cause other than Diabetes

The patients were questioned about the presence of symptoms like postural giddiness and nocturnal polyuria, disturbances of bladder sphincter, constipation, diarrhea, impotence and bouts of localized sweating. All the patients were subjected to a detailed clinical examination. Glycosylated hemoglobin levels were assessed in all diabetic patients. The following tests were performed to assess the autonomic functions in the patients ${ }^{8,9}$ :

1. Tests reflecting Parasympathetic functions:

a. Heart rate variation during deep breathing.

b. Heart rate response to Valsalva Maneuver

c. Immediate Heart rate response to Standing.

2. Tests reflecting Sympathetic functions:

a. Blood pressure response to standing.

b. Blood pressure response to sustained handgrip.

3. Corrected QT-interval in the electrocardiogram, to assess cardiac autonomic neuropathy features.

Normal, borderline and abnormal values in tests for autonomic functions ${ }^{10,11}$ :
Majority of patients were males (72\%). $92 \%$ of the cases had at least one symptom of Autonomic dysfunction in comparison, while only $12 \%$ of the controls presented with had at least one symptom of Autonomic dysfunction. Among them significant proportion patients (70\%) were diabetic for 5-8 years duration. Among the cases, Impotence was the commonest symptom, (35\%) followed by postural giddiness $(32 \%)$ as shown in Figure 1.

As per figure 1, Impotence is the commonest symptom of autonomic dysfunction and polyneuropathy the commonest complication followed by postural giddiness. Among the 50 cases, 32 of them had positive Autonomic scores (64\%). Among controls 5 of them had positive autonomic scores(10\%).Autonomic positive scores were significantly more in Cases compared to Controls with $P<0.001$ as shown in table 1.

Polyneuropathy was the commonest complication among the cases (44\%), next being retinopathy (34\%) and nephropathy (32\%). Of the 22 cases of polyneuropathy, 17 had positive autonomic scores (77\%). Hence there was a very association between polyneuropathy, retinopathy and nephropathy with autonomic neuropathy among diabetics as shown in table 2 . Mean Glycosylated Haemoglobin (HbA1c) was $8.24 \pm 2.59 \%$. Among the cases the mean $\mathrm{HbA} 1 \mathrm{C}$ for

\begin{tabular}{|c|c|c|c|}
\hline Tests & Normal values & $\begin{array}{l}\text { Borderline } \\
\text { values }\end{array}$ & $\begin{array}{l}\text { Abnormal } \\
\text { values }\end{array}$ \\
\hline \multicolumn{4}{|l|}{ A. Parasympathetic Function Tests } \\
\hline 1. Heart rate variation during deep breathing & $\begin{array}{l}15 \text { or more } \\
\text { (beats } / \mathrm{min} \text { ) }\end{array}$ & $\begin{array}{c}11-14 \\
\text { (beats/min) }\end{array}$ & $\begin{array}{c}10 \text { or less } \\
\text { (beats/min) }\end{array}$ \\
\hline 2. Immediate heart rate response to standing $\left(30: 15 \mathrm{ratio}^{* *}\right)$ & 1.04 or more & $1.01-1.03$ & 1.00 or less \\
\hline 3. Heart rate response to valsalva maneuver (valsalva ratio*) & 1.21 or more & $1.11-1.20$ & 1.10 or less \\
\hline \multicolumn{4}{|l|}{ B. Sympathetic Function Tests } \\
\hline 1. B.P response to standing (fall in systolic blood pressure) & $\begin{array}{c}10 \text { or less } \\
(\mathrm{mm} \text { of } \mathrm{Hg})\end{array}$ & $\begin{array}{c}11-29 \\
(\mathrm{~mm} \text { of } \mathrm{Hg})\end{array}$ & $\begin{array}{l}30 \text { or more } \\
(\mathrm{mm} \text { of } \mathrm{Hg})\end{array}$ \\
\hline 2. B.P response to handgrip (increase in diastolic blood pressure) & $\begin{array}{l}16 \text { or more } \\
(\mathrm{mm} \text { of } \mathrm{Hg})\end{array}$ & $\begin{array}{c}11-15 \\
(\mathrm{~mm} \text { of } \mathrm{Hg})\end{array}$ & $\begin{array}{c}10 \text { or less } \\
(\mathrm{mm} \text { of } \mathrm{Hg})\end{array}$ \\
\hline \multicolumn{4}{|c|}{$\begin{array}{l}\text { *Valsalva ratio is the ratio of the longest } R R \text { interval after the maneuver to the shortest interval during the maneuver. } \\
\text { ** the shortest } R R \text { interval at around } 15 \text { th beat and longest } R R \text { interval at around } 30 \text { th beat are measured which is } \\
\text { characteristically expressed by the } 30: 15 \text { ratio. } \\
\text { For every abnormal value, Points given }=2 \\
\text { For every borderline value, Points given }=1 \\
\text { For every normal value, Points given }=0 \\
\text { Of total sum of } 10 \text {, if total score obtained from tests is }>5 \text {, i.e } 6 \text { or above, it is considered positive autonomic Score. }\end{array}$} \\
\hline
\end{tabular}

\section{STATISTICAL ANALYSIS ${ }^{12,13}$}

Results on continuous measurements are presented on Mean $\pm \mathrm{SD}$ (Min-Max) and results on categorical measurements are presented in Number (\%). Significance is assessed at $5 \%$ level of significance. Chi-square/ Fisher Exact test has been used to find the significance of study parameters on categorical scale between two or more groups. Data was analyzed based on descriptive statistics, by means of proportions and percentages, and depicted by bar diagrams.

\section{RESULTS}

The average age group of patients was between 45-60 years. those with negative autonomic scores was $5.98 \pm 1.41 \%$ as compared to $7.24 \pm 2.42 \%$ in those with positive Autonomic scores.

The mean heart rate response to deep breathing among cases was $13.26+/-5.25$ and that among controls was $21.0+/-5.1$ $(\mathrm{P}<0.001)$. BP response to hand grip in cases was $14.03+/-$ 5.11 and that among controls was $17.91+/-3.05(\mathrm{P}<0.001)$. Hence a significant positive autonomic cardiovascular reflex was noted among cases than controls as shown in table 3.

Prolonged Corrected QT-interval, of more than 0.44 seconds was noted among the cases (46\%) as compared to controls (6\%). 4 out of the 10 Type 1 Diabetics had prolonged 


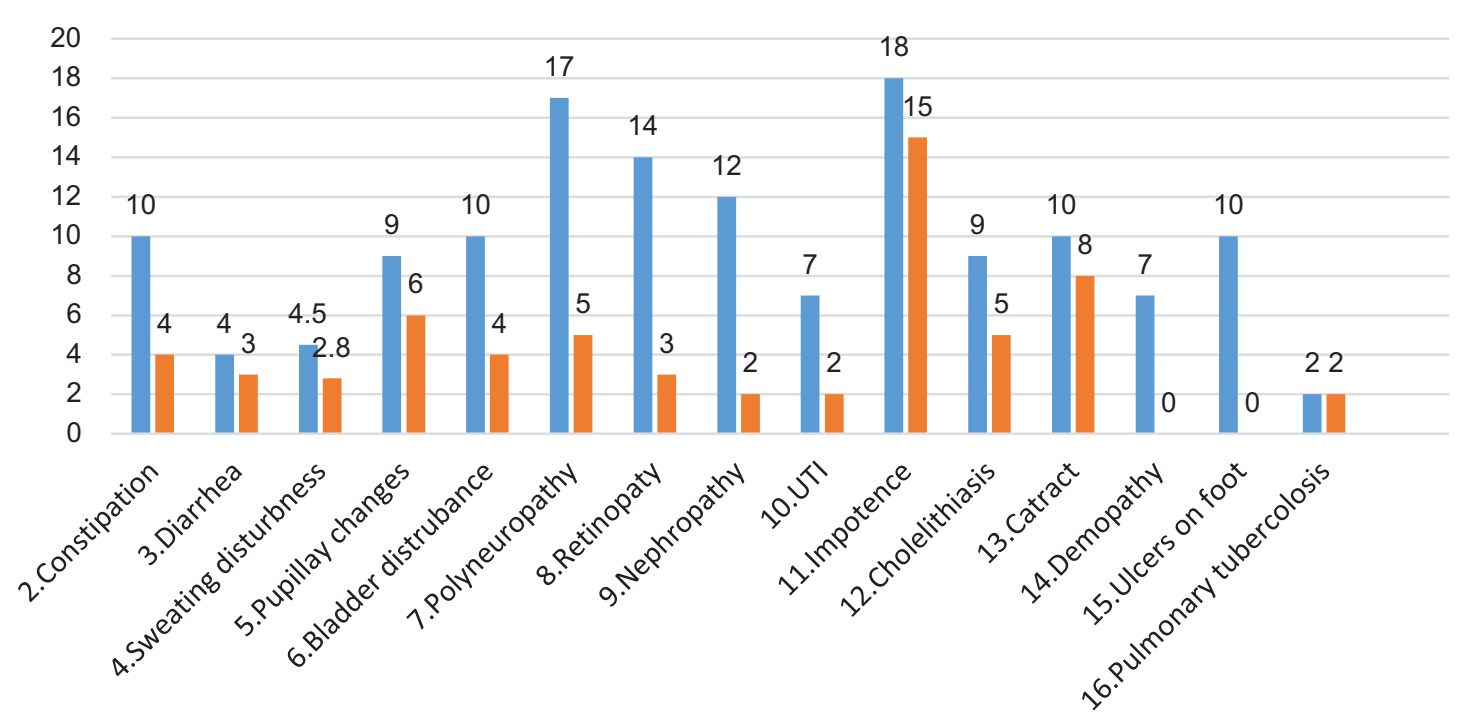

Figure-1: Presenting complaints among the subjects

\begin{tabular}{|l|c|c|c|c|}
\hline \multirow{2}{*}{ Autonomic score } & \multicolumn{2}{|c|}{ Cases } & No & Controls \\
\cline { 2 - 5 } & No & $\%$ & 45 & 90.0 \\
\hline Negative $(<=5.0)$ & 18 & 36.0 & 5 & 10.0 \\
\hline Positive $(>5.0)$ & 32 & 64.0 & 50 & 100.0 \\
\hline Total & 50 & 100.0 & \\
\hline \multicolumn{2}{|c|}{ Table-1: Distribution of Autonomic scores among the subjects } \\
\hline
\end{tabular}

\begin{tabular}{|l|c|c|c|c|}
\hline Complications & \multicolumn{2}{|c|}{ Diabetics with autonomic neuropathy } & \multicolumn{2}{c|}{ Diabetics without autonomic neuropathy } \\
\hline & Number & Percentage & Number & Percentage \\
\hline Polyneuropathy & 17 & 77 & 5 & 23 \\
\hline Nephropathy & 12 & 86 & 2 & 14 \\
\hline Retinopathy & 14 & 82 & 3 & 18 \\
\hline \multicolumn{2}{r}{} \\
\hline
\end{tabular}

\begin{tabular}{|l|c|c|c|}
\hline & Cases & Controls & P value \\
\hline Heart rate response to deep breathing & $13.26 \pm 5.25$ & $21.0 \pm 5.10$ & $<0.001$ \\
\hline Heart rate response to valsalva maneuver & $1.17 \pm 0.28$ & $1.18 \pm 0.99$ & $<0.001$ \\
\hline Immediate heart rate response to standing & $1.42 \pm 0.14$ & $1.37 \pm 0.19$ & 0.001 \\
\hline B.P response to handgrip Table-3: Cardiac response in cases and controls & $<0.001$ \\
\hline \multicolumn{2}{|c|}{} \\
\hline
\end{tabular}

\begin{tabular}{|l|c|c|}
\hline Treatment & Number of patients & $\%$ \\
\hline Insulin & 17 & 34.0 \\
\hline OHA & 22 & 44.0 \\
\hline Insulin + OHA & 11 & 22.0 \\
\hline Total & 50 & 100.0 \\
\hline \multicolumn{2}{|c|}{ Table-4: Treatment options in cases } \\
\hline
\end{tabular}

corrected QT-interval (40\%). Among the cases the corrected QT-interval was $6.46 \pm 0.79$ seconds for those with positive autonomic scores than $1.38 \pm 1.20$ seconds in those with negative scores.

There is a significant decrease in number of tests being positive among those who take both insulin and Oral Hypoglycemics, as against those who take either one as shown in table 4

\section{DISCUSSION}

Age of the patients ranged from 18 - 70 years. Nearly 36\% cases belonged to age group 45-60 years. In comparison, the maximum number of controls also belonged to the 51-60 age group (32\%). Hence the age distribution is matched among the two groups. In this study maximum number of patients had duration of the disease between 5-8 years i e. 70\%.

In this study, 46 out of the 50 diabetes patients studied, presented with symptoms suggestive of autonomic neuropathy in the form of impotence, postural giddiness, constipation, sweating disturbances, bladder disturbances and diarrhea. Impotence was the most common symptom in this study which was seen in 35\% cases. Noronha J.L., Bhandarkar S.D., et al. found impotence in $52 \%$ of their study diabetic subjects, being the commonest symptom ${ }^{13}$. Gupta, et al in 
their study noted 12 patients with impotence in 50 diabetic patients ${ }^{14}$. Ina study by Rundles et al. noted impotence in 19 patients out of 125 diabetic patients ${ }^{15}$ Postural giddiness was the next common symptom seen in $32 \%$ cases. $77 \%$ patients with polyneuropathy had evidence of autonomic neuropathy. Aaron I. Vinik, Raelene E. Maser, et al found that the most commonly autonomic neuropathy occurs with diabetic polyneuropathy and nephropathy. ${ }^{16}$ Mackay et al. found an association of $55 \%$ between peripheral neuropathy and autonomic neuropathy ${ }^{17}$. Nijhawan et al.found an association of $60 \%{ }^{18}$. Rajiv A. Gandhi et al. found increased incidence of peripheral neuropathy in diabetic dysautonomia ${ }^{19}$.Patients with retinopathy had associated autonomic neuropathy in 14 out of 17 patients (82\%) of cases.Patients with nephropathy were associated with autonomic neuropathy in 12 out of $14(86 \%)$ of patients. This shows a good association of nephropathy with autonomic neuropathy among diabetics.

Poor glycemic control is associated with diabetic complications and notably with autonomic neuropathy. The mean value of glycosylated haemoglobin was $7.24 \pm 2.42 \%$. Cases with positive autonomic scores had uncontrolled blood sugars (fasting and post-prandial blood sugars), than those with negative scores. Those with positive scores had a mean value of glycosylated haemoglobin of $7.24 \pm 2.42 \%$ as against that of $5.98 \pm 1.41 \%$ in those with negative scores. J.M.Pappachan et al. in their study noticed that the incidence of diabetic autonomic neuropathy increased with increasing duration and poor glycemic control ${ }^{20}$.

In this study the corrected QT interval was significantly increased among diabetic cases compared to controls. The mean corrected QT interval was 6.46 \pm 0.79 among those with positive autonomic scores, as compared to a corrected QT interval of $1.38 \pm 1.20$ among those without negative autonomic scores. This is statistically significant. J.M.Pappachan et al. also noted a significant association between CAN and prolonged corrected QT interval ${ }^{20}$.

\section{CONCLUSION}

We conclude that there is an increased incidence of autonomic neuropathy among Diabetics. There is a significant correlation between Polyneuropathy and Autonomic neuropathy in Diabetics. Simple bed side tests and ECG (with prolonged corrected QT-interval in a diabetic) is mandatory and should prompt the physician regarding the autonomic complications. Early detection, treatment and lifestyle modifications will decrease the incidence of Autonomic dysfunction as there will be a good glycemic control.

\section{Limitations of study}

Small sample size. Overt nutritional defeciences that may cause polyneuropathy. Such patients were not identified and excluded in the study.

\section{REFERENCES}

1. Michael Brownlee, Lloyd. P. Aiello, Mark.E.Cooper, William's textbook of Endocrinology, $11^{\text {th }}$ edition, chapter 32, 1418-1490

2. Harrison's Principles of Internal Medicine, Autonomic Neuropathy in Diabetes Mellitus, Chapter 338, $17^{\text {th }}$ edition, pg.2289-2293.
3. Suraj Kupa and Virend K. Somers. Cardiovascular manifestations of Autonomic Disorders, Braunwald's Heart Disease: A textbook of Cardiovascular Diseases, $8^{\text {th }}$ Edition, WB Saunders, 2008, pgs 2171-2183

4. Das K. Ashok. Diabetic Autonomic Neuropathy. Clinical features diagnosis and management. Novo Nordisk update. 29-37, 1994.

5. A P I Textbook of Medicine, Diagnosis of Diabetes Mellitus, 10th edition, vol. 2, pages 1049-1051

6. Armstrong C. ADA updates standards of medical care for patients with diabetes mellitus. American family physician. 2017;95(1):40-3.

7. Cornell S. Comparison of the diabetes guidelines from the ADA/EASD and the AACE/ACE. Journal of the American Pharmacists Association. 2017;57(6):261-5.

8. D J Ewing, I W Campbell, A Murray, J M M Neilson, B F Clarke. Immediate heart-rate response to standing: simple test for autonomic neuropathy in diabetes. British Medical Journal, 1978;1(3):145-147

9. Ewing D.J et al. Autonomic neuropathy - its diagnosis and prognosis. Clinics $m$ endocrinology and metabolism 1986;15(2):855 885 .

10. Ewing D.J et al. The value of cardiovascular autonomic function tests, 10 years experience in diabetes. Diabetes care. 2011;8(4):441 - 498

11. Bernard Rosner (2000), Fundamentals of Biostatistics, $5^{\text {th }}$ Edition, Duxbury, page 80-240

12. M. Venkataswamy Reddy (2002), Statistics for Mental Health Care Research, NIMHANS publication, INDIA, page 108-144

13. Noronha J.L., Bhandarkar S.D., Shenoy P.N., Retnam V.J. Autonomic Neuropathy in Diabetes Mellitus, J Postgrad Med 1981; 27(5): 1-6

14. R.C.Gupta, M.D. Chittora, A. Jain. A study of Autonomic Neuropathy in Diabetes Mellitus in relation to its metabolic control JAPI 1995;43(1):7-10.

15. Rundle RW. Diabetic neuropathy. Medicine (Baltimore) 24.111-160, 1945.

16. Aaron I. Vinik, Raelene E. Maser, Braxton D. Mitchell, Roy Freeman. Diabetic Autonomic Neuropathy. Diabetes Care 2003;26(5):1553-79.

17. Mackay $\mathrm{T}$ et al. Autonomic neuropathy. Diabetologia. 1980;18(3):471 -478.

18. Nijhawan S, et al. Autonomic and peripheral neuropathy in insulin dependent diabetes. Joint Association of Physicians of India. 1993;41(6):565-566,

19. Rajiv A. Gandhi, Jefferson L.B. Marques. Painful Diabetic Neuropathy Is Associated With Greater Autonomic Dysfunction than Painless Diabetic Neuropathy. Diabetes Care 2010;33(2):1585-1590,

20. J.M.Pappachan, J.Sebastian, B.C. Bino, et al, Cardiac Autonomic Neuropathy in Diabetes Mellitus: prevalence, risk factors and utility of Corrected QT interval in the ECG for its Diagnosis. Postgrad Med J 2008;84(990):205-10.

\section{Source of Support: Nil; Conflict of Interest: None}

Submitted: 15-04-2020; Accepted: 17-05-2020; Published online: 30-06-2020 